Nachtrag zu der Arbeit über

\title{
"Meningitis carcinomatosa“.
}

Von

Ed. Sehwarz, Riga.

In unserer Arbeit über M. carcinomatosa im vorigen Heft dieser Zeitschrift ist leider nicht über die erste einschlägige Arbeit berichtet worden; uns war dieselbe entgangen.

In der Nr. 23 des Neurologischen Zentralblatts 1901 hat Herr Sänger-Hamburg als erster einen ähnlichen Fall publiziert and ist somit auch der erste gewesen, der darauf hingewiesen hat, dass man sich in solchen Fällen nicht auf die makroskopische Inspektion des Rückenmarks allein verlassen kann. 